\title{
Development of Large Grain/Single Crystal Niobium Cavity Technology at Jefferson Lab
}

P. Kneisel, G. Ciovati and G.R.Myneni, Jefferson Lab

J. Sekutowicz, DESY

T. Carneiro, CBMM 
* Overview

What has been done

What will be done in the future

* Test Series

$\checkmark$ Comparison of Material from different Vendors

$\checkmark$ Single Crystal Cavity Performance Anodization Tests/T-Mapping:

Understanding Q -drop 


\section{Jlab/CBMM Collaboration}

- Development started $\sim 2$ years ago with the need for understanding mechanical properties of niobium from different manufacturers (G. Myneni)

- Ingot material supplied by CBMM with large grains (T. Carneiro)

- Mechanical properties - especially elongation - excellent, permitting forming of cavity cells

- Investigate influence of grain boundaries on "Q-drop"

Comparison of Single and Poly Crystal RRR niobium

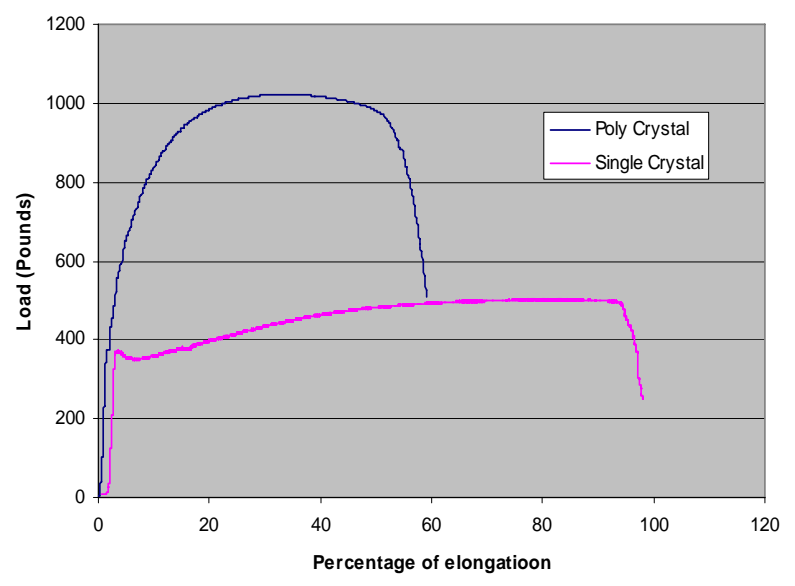




\section{Activities at JLab}

- Jlab received a grant from ILC America to explore the potential of large grain/single crystal niobium for high performance cavity application

- Metallurgical/material investigations in collaboration with NIST(spring back, formability, residual stress, internal friction, interstitial interactions..) and NCSU (oxidation behaviour for different crystal orientations)

- Exploration and evaluation of material from different vendors with different properties/ cost effectiveness

- Development of "streamlined" procedures, e.g. BCP vs EP, material removal, "in situ " baking...

- Shedding some light in the mechanism of "Q-drop" 


\section{What has been done}

- Cavities have been fabricated and tested from 4 different manufacturers:

CBMM ( 4 different ingots)

Ningxia ( 3 different ingots)

W.C. Heraeus ( 2 different ingots, 1 used for single crystal-DESY)

Wah Chang ( 1 ingot)

- The material has been cut by wire EDM, saw cutting + machining, and wire saw cutting

- Single cell cavities ranging in frequency from $1300 \mathrm{MHz}$ to $2300 \mathrm{MHz}$ of different shapes and beta values (TESLA, LL_ILC,OC,HG,LL, PD) have been fabricated and tested

- Multi-cell cavities (2 HG (7-cell), LL_ILC(7 cell) have been fabricated and tested or are under test

- In total we have fabricated and tested 17 single cell cavities and 3 multi-cell cavities and carried out close to 100 tests 


\section{Large Grain/Single Crystal Niobium[2]}

\section{CBMM}

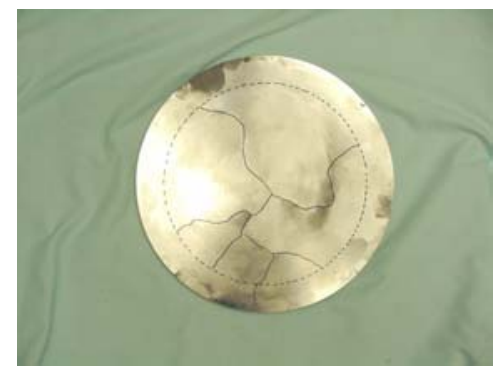

Ingot “D”,800 ppm Ta

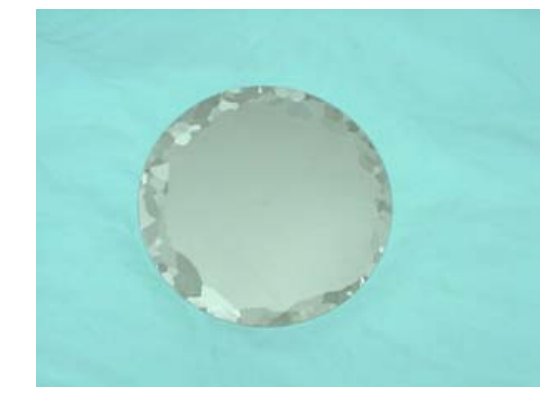

Ingot “A”, 800 ppm Ta

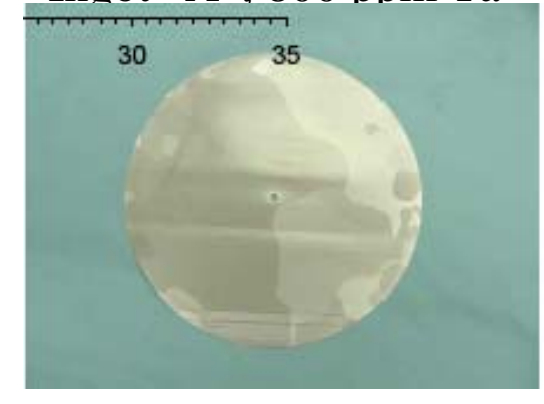

Oct. 30 - Nov. 2, 2006 Ingot “B”, 800 ppm Ta

\section{Ninxia}
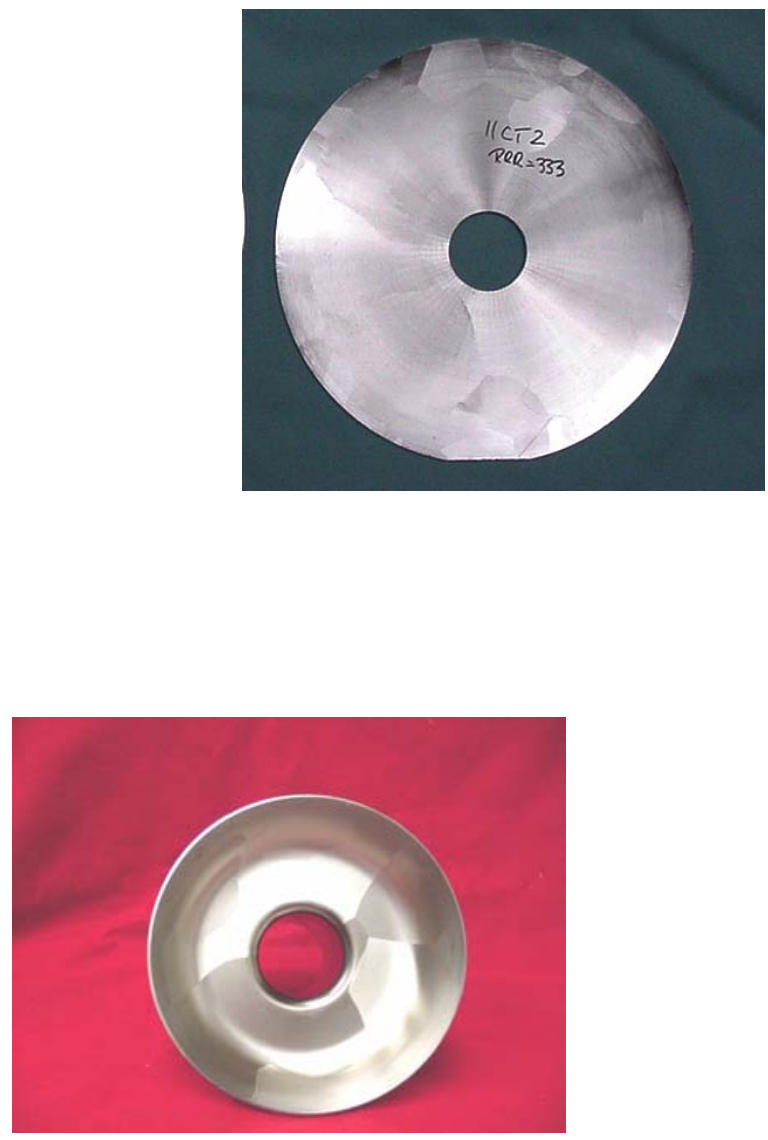

Ingot “C”, 1500 ppm Ta
Wah Chang

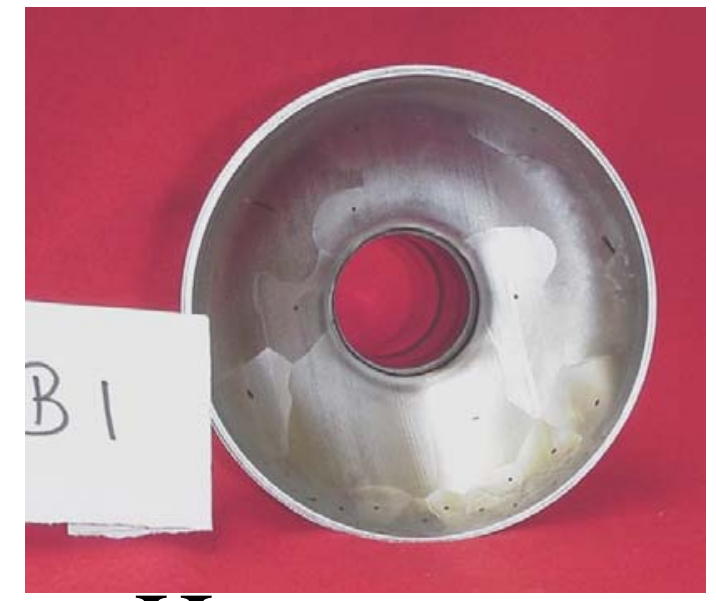

Heraeus
Single Crystal Workshop Araxa, Brasil 


\section{CBMM Ingot “E”}

RRR- value : $300 \quad$ Ta- contents: 490 ppm

1 TESLA single cell cavity

1 ILC LL single cell cavity

are being fabricated

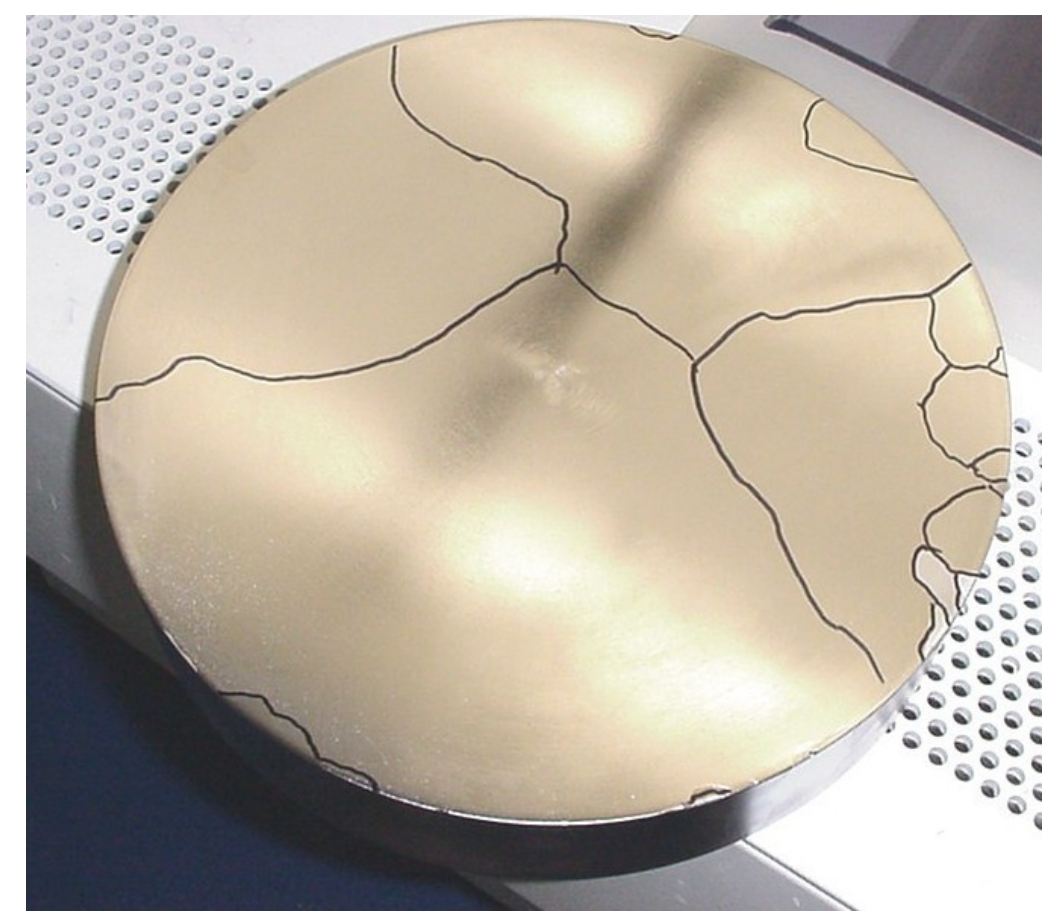

Oct. 30 - Nov. 2, 2006 


\section{Summary of large grain/single crystal single cell tests(1)}

- 9 different ingots with different properties (RRR,Ta)

- 15 different cavities (1300 MHz to $2300 \mathrm{MHz}$ )

- Different treatments (cutting/bcp/anodizing/furnace/material removals)

- All tests after in-situ baking ( 3 hrs to 48 hrs, vacuum/oxygen/air)

- All tests - N = 51 after "in-situ” baking - limited by "quench" 


\section{Test Results (Jlab)}

- In all tests/all cavity types the cavity performances were limited by "Quench"

- Therefore, for comparing the results, the magnetic quench field is the right property to look at

- For "calibration" the table below lists the required performance in terms of $\mathrm{H}_{\max }$ for ILC and XFEL cavities

\begin{tabular}{|l|l|l|}
\hline Project & $\mathrm{E}_{\mathrm{acc}}[\mathrm{MV} / \mathrm{m}]$ & $\mathrm{H}_{\max }[\mathrm{mT}]$ \\
\hline XFEL & 28 & 119 \\
\hline ILC(BCD) & 35 & 149 \\
ILC (ACD) & 45 & 162 \\
\hline
\end{tabular}




\section{Test Results (Jlab)}

- The measured "quench fields" for the different large grain materials and cavity types ranged for 1-cells between

$$
121 \mathrm{mT}<\mathrm{H}_{\text {quench }}<160 \mathrm{mT}
$$

- The single crystal cavities ( two at $2.2 \mathrm{GHz}$, one at 1300 $\mathrm{MHz}$ provided by DESY) had quench fields of

$$
150 \mathrm{mT}<\mathrm{H}_{\text {quench }}<160 \mathrm{mT}
$$

- In all of the multi-cell cavities we encountered fabrication problems ( holes during EBW, tuning problems) and the results were inferior: best result was a quench field of 114 $\mathrm{mT}$. Further tests will follow 


\section{Summary of large grain/single crystal single cell tests(2)}

Jlab
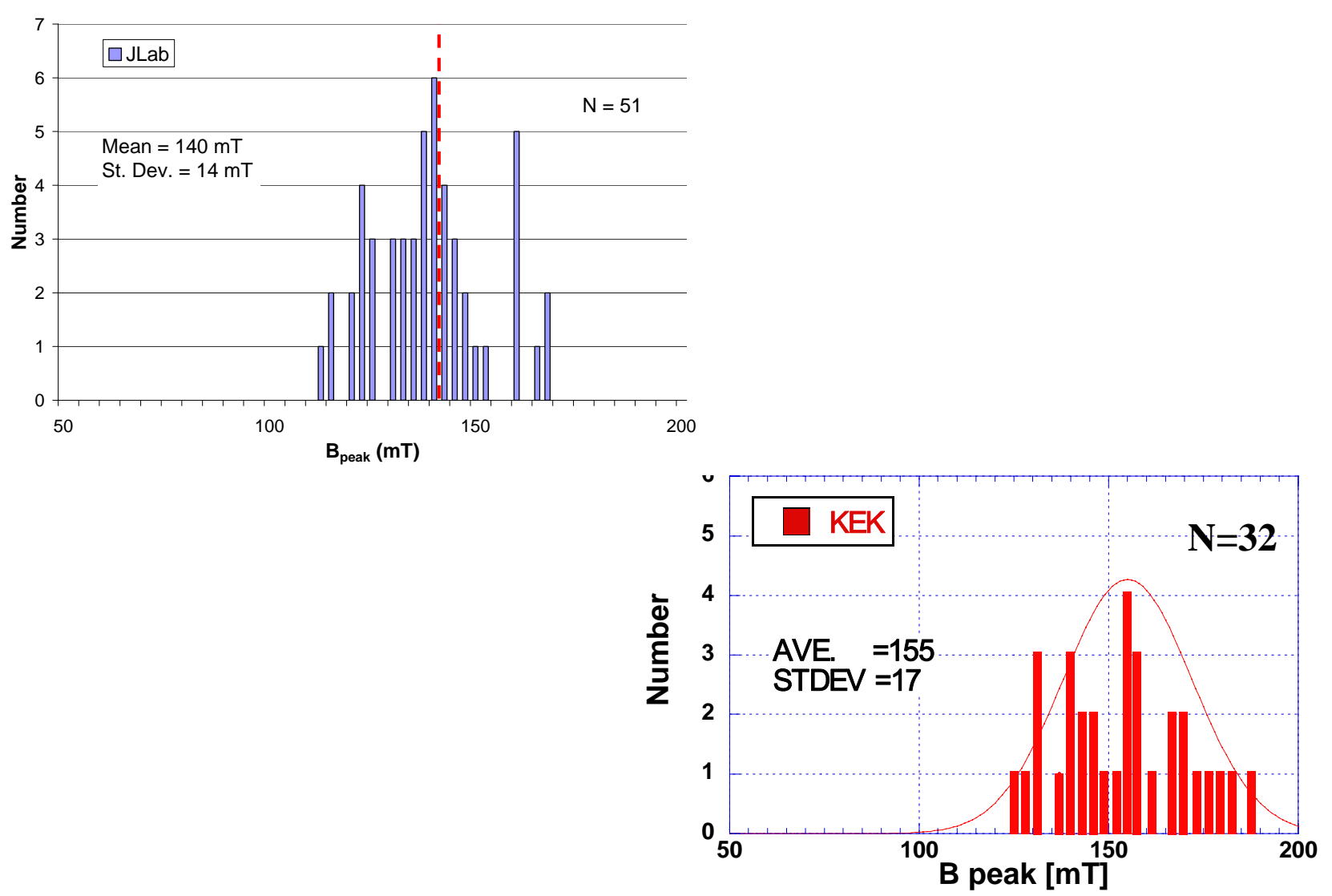

Oct. 30 - Nov. 2, 2006

Single Crystal Workshop
KEK

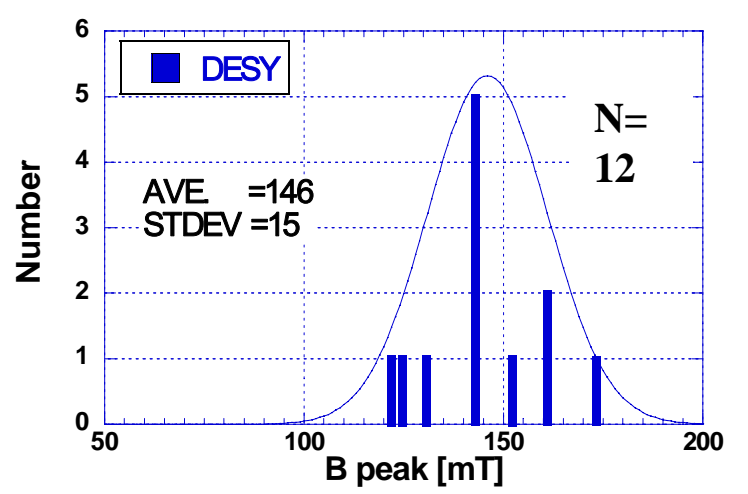

\section{DESY}

Araxa, Brasil 


\section{Plans: What is in the "pipeline"?}

- Two 9-cell TESLA cavities (nearly completed, for FNAL)

- Five single cell TESLA-type cavities from Ningxia Niobium (in fabrication)

- One TESLA-type single cell from CBMM ingot”E”(in fabrication)

- One ILC_LL single cell from CBMM ingot "E” (in fabrication)

- One 1-Amp FEL single cell from CBMM ingot "B" ( in fabrication)

- One 5-cell 1-Amp FEL cavity from CBMM ingot”B” (in fabrication)

- Two "single crystal" TESLA-type cavities from CBMM ingot "B" in collaboration with DESY( X. + W. Singer)

- Five ILC_LL single cell cavities from W.C.Heraeus niobium (waiting for material, some fabrication of beam pipes,flanges) 


\section{What did we learn?}

Oct. 30 - Nov. 2, 2006 


\section{Fabrication Issues (1)}

- Large grain sheets deep draw with ragged edges

- Sometimes the material is thinning or ripping at the irises, if the grains "meet" in these areas

- There is some spring back after the deep drawing, making the half cells "oval"

- The same happens after the trimming for EBW

- Assembly for EBW sometimes more difficult than with fine grain material. However, no problem with single crystals

- On a few occasions, holes occurred during welding 


\section{Fabrication Issues (2)}

Half cell from CBMM Ingot "B"

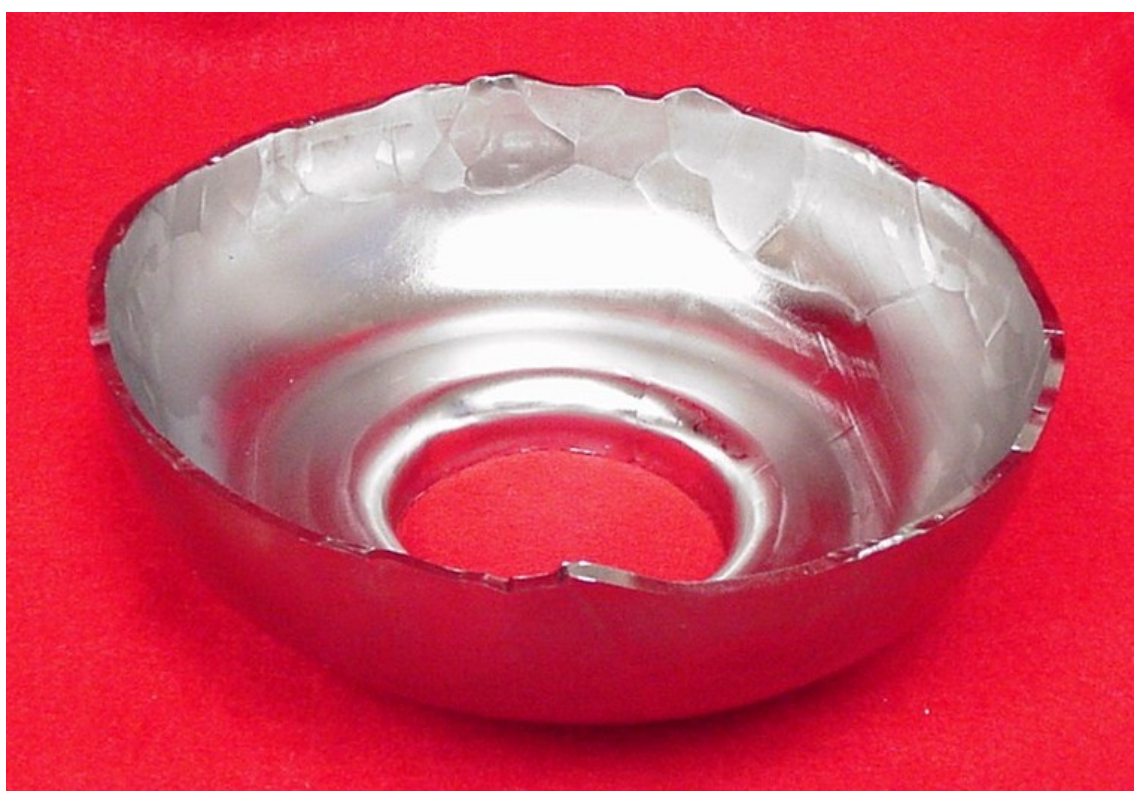

Oct. 30 - Nov. 2, 2006

Single Crystal Workshop

Araxa, Brasil 


\section{R \& D Topics}

During the course of our work in the last 2 years, we have identified several R\&D topics

- Effective cutting: wire EDM too slow?

- Forming: how uniform, grain slippage

- Welding/Vacuum: do grain boundaries cause problems?

- Surface roughness: appropriate acid agitation during bcp, uniformity of material removal

- Mechanical properties depending on grain orientation?

- Internal stresses and strains due to deep drawing using neutron diffraction techniques

- Dependence of oxidation on grain orientation 


\section{Heraeus}

\section{High purity Niobium RRR discs cutted from ingot}

- first discs with a big central grain

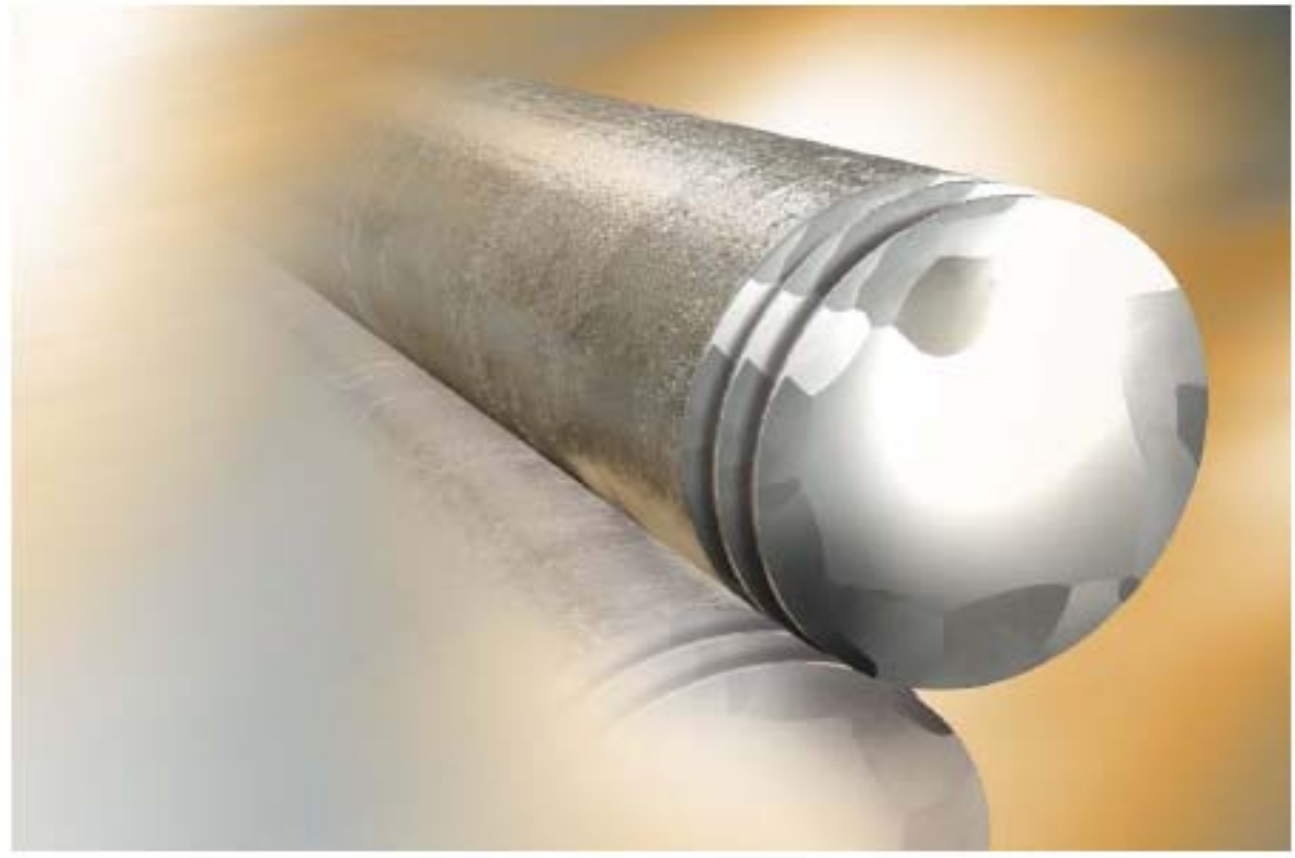

B.Spaniol,LINAC 2006,paper TUP024

Oct. 30 - Nov. 2, 2006

Single Crystal Workshop

Araxa, Brasil 


\section{Surface Roughness}

BCP provides very smooth surfaces (A.Wu, Jlab)

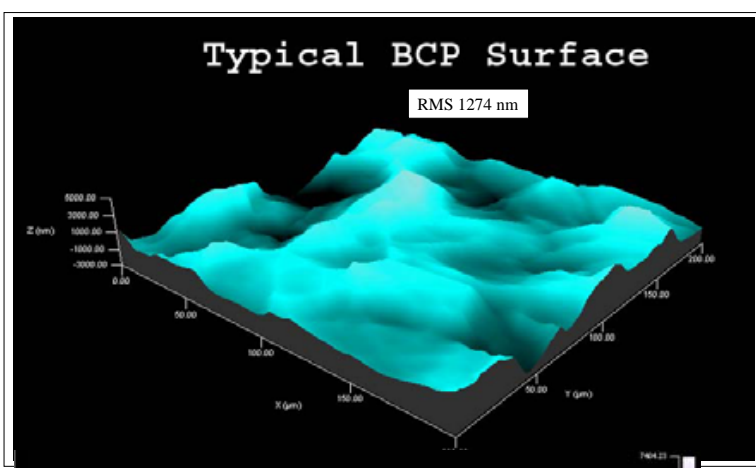

RMS: $1274 \mathrm{~nm}$ fine grain bcp

$53 \mathrm{~nm}$ after $\sim 35$ micron, single Crys $27 \mathrm{~nm}$ after $\sim 80$ micron, single Crys $251 \mathrm{~nm}$ fine grain ep

Mechanical Polish followed by BCP112 20 Min RMS 53nm

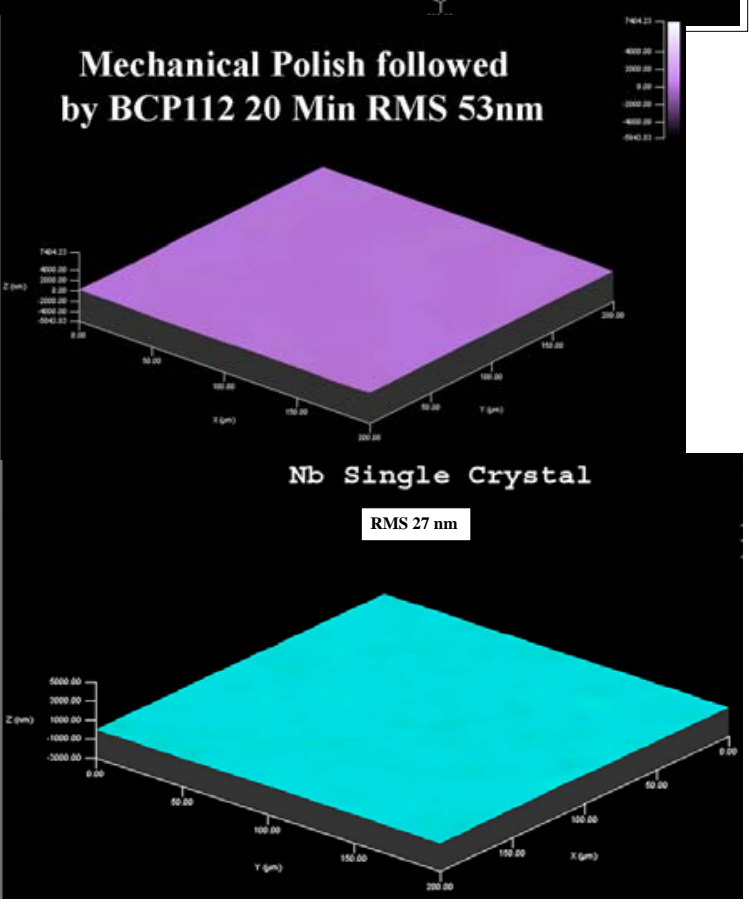

Oct. 30 - Nov. 2, 2006

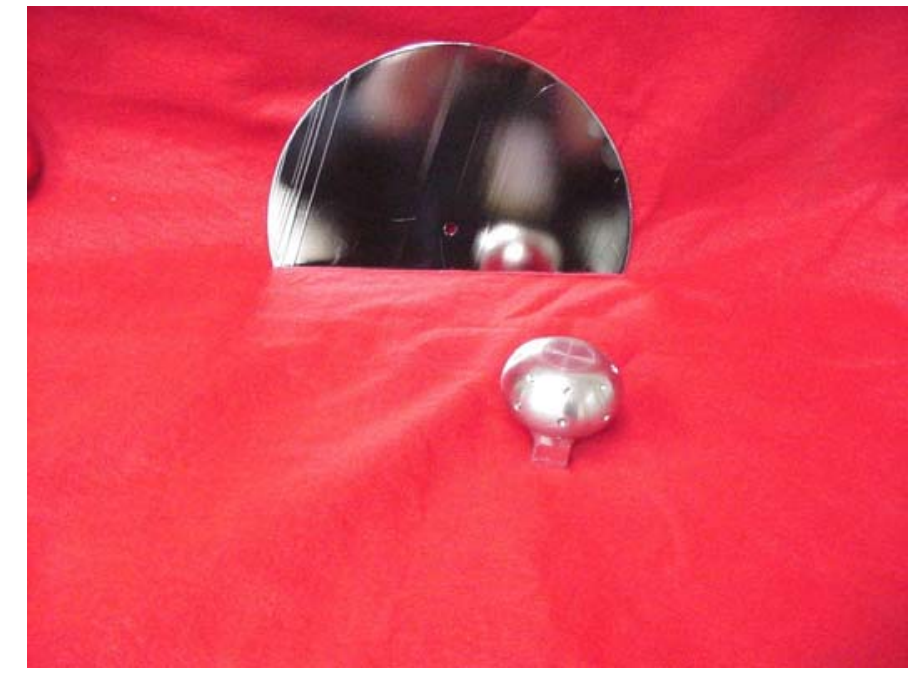

Single Crystal Workshop

Araxa, Brasil 


\section{Potential Benefits of Single Crystal Nb}

- Reduced costs

- Comparable performance

- Very smooth surfaces with BCP, no EP necessary

- Better Cleaning ( FE reduction?)

- Elimination of Q-drop with short baking times

- Less material QA (eddy current/squid scanning)

- Possibly very low residual resistances (high Q's), favoring lower operation temperature(B.Petersen)

- Higher thermal stability because of "Phonon-Peak"

- Good or better mechanical performance than fine grain material (e.g.predictable spring back..) 


\section{Potential Benefits of Single Crystals}

- Very smooth surface finish with BCP only

- Better cleaning ( less FE ?)

Mechanically polished,

90 micron bcp 1:1:2

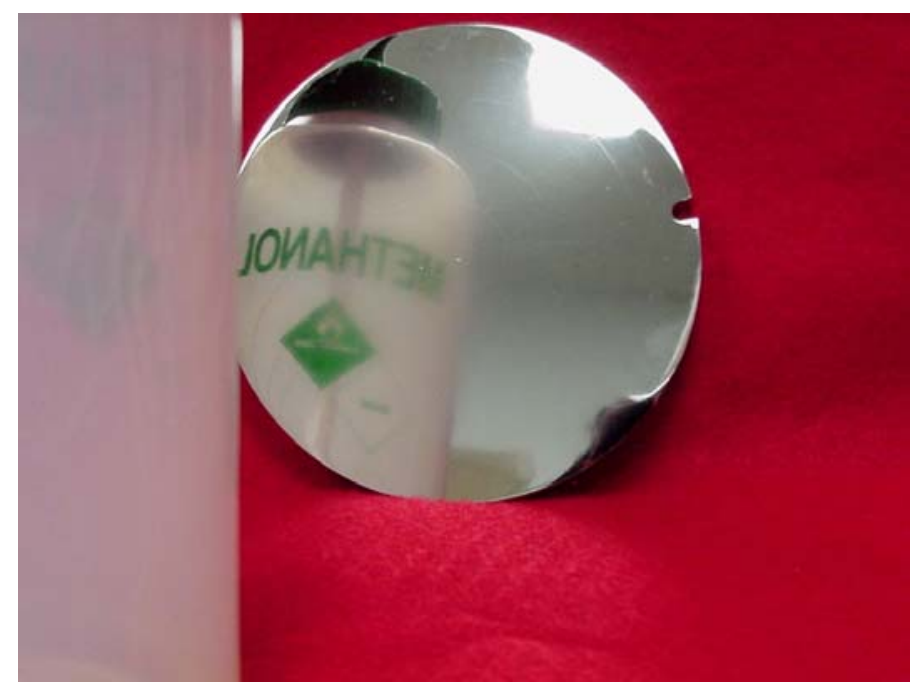

FE studies at Univ.Wuppertal (A.Dangwal, G. Mueller)

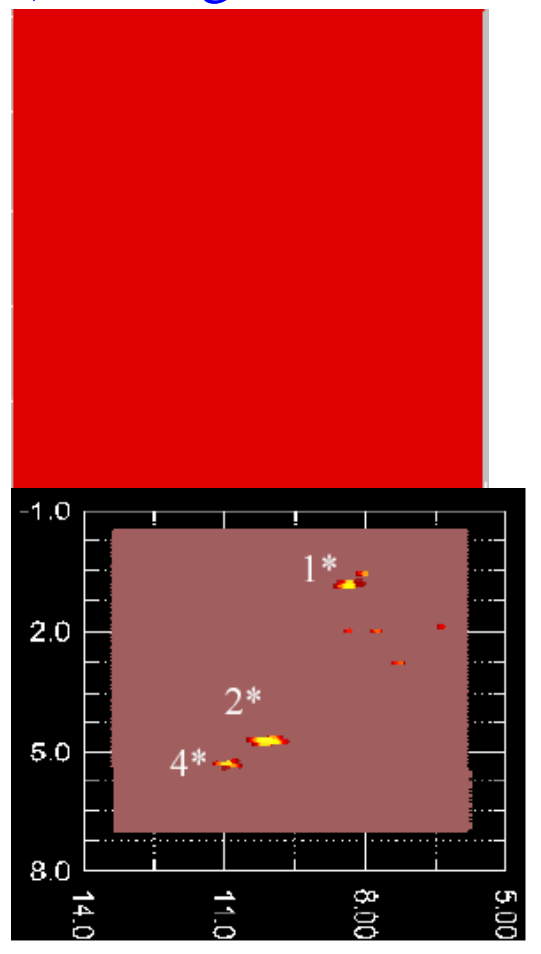

Single crystal, bcp 35 micron

E - $120 \mathrm{MV} / \mathrm{m}$

0 emitters

Poly-crystal

$\mathrm{E}=120 \mathrm{MV} / \mathrm{m}$

8 emitters

Oct. 30 - Nov. 2, 2006

Single Crystal Workshop

Araxa, Brasil 


\section{Single Crystal Cavity(1): CBMM Ingot”A”}

HG Cavity Shape:2.3 GHz

ILC LL cavity Shape:2.3 GHz

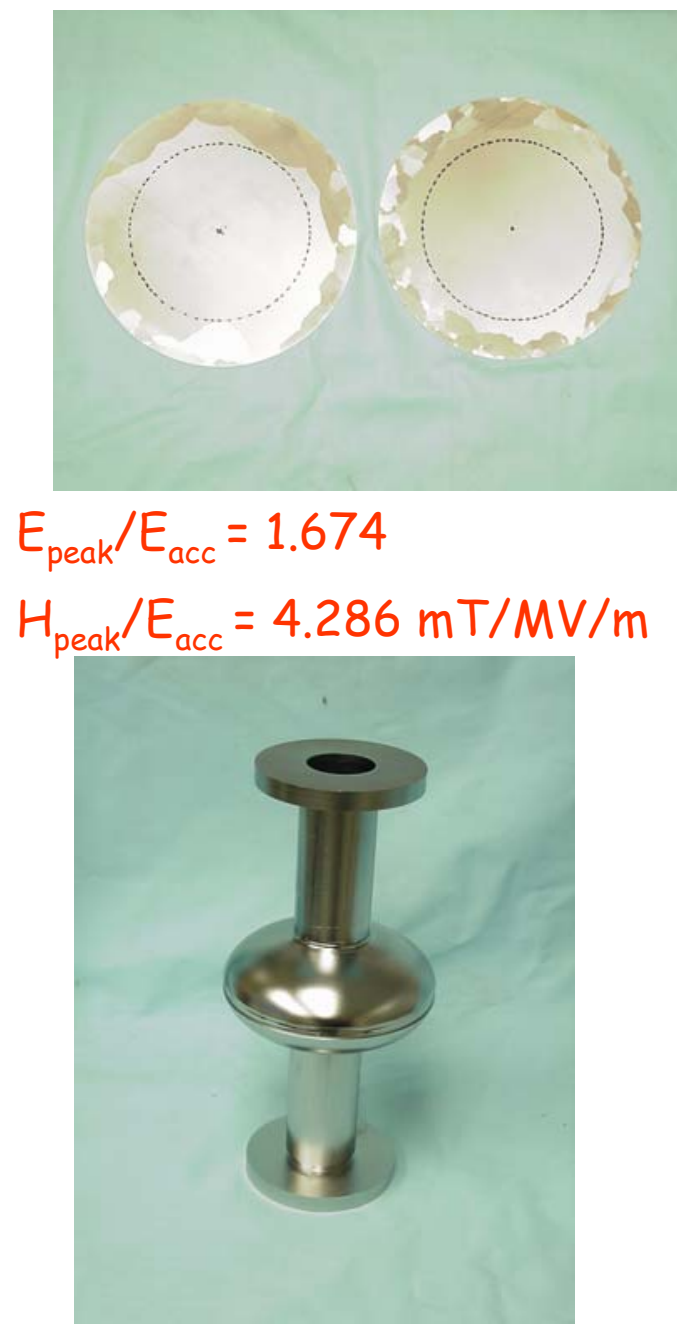

Oct. 30 - Nov. 2, 2006

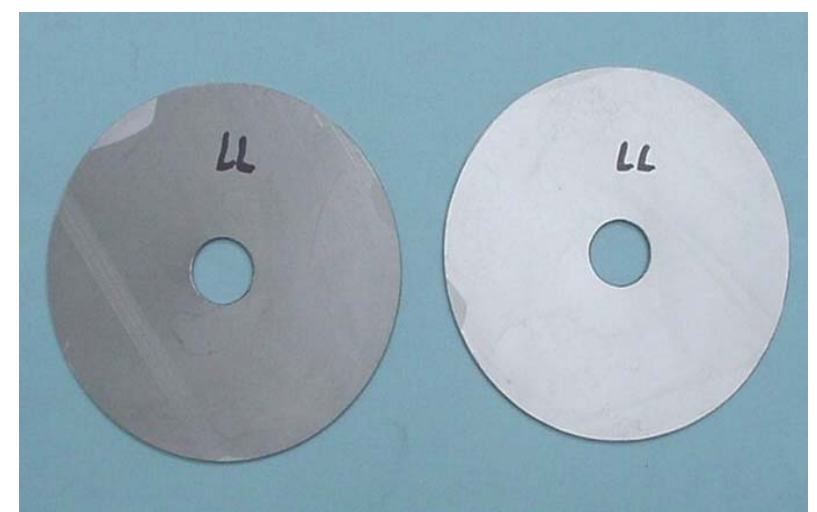

$$
\begin{aligned}
& E_{\text {peak }} / E_{\text {acc }}=2.072 \\
& H_{\text {peak }} / E_{\text {acc }}=3.56 \mathrm{mT} / \mathrm{MV} / \mathrm{m}
\end{aligned}
$$




\section{Single-crystal cavities(2)}

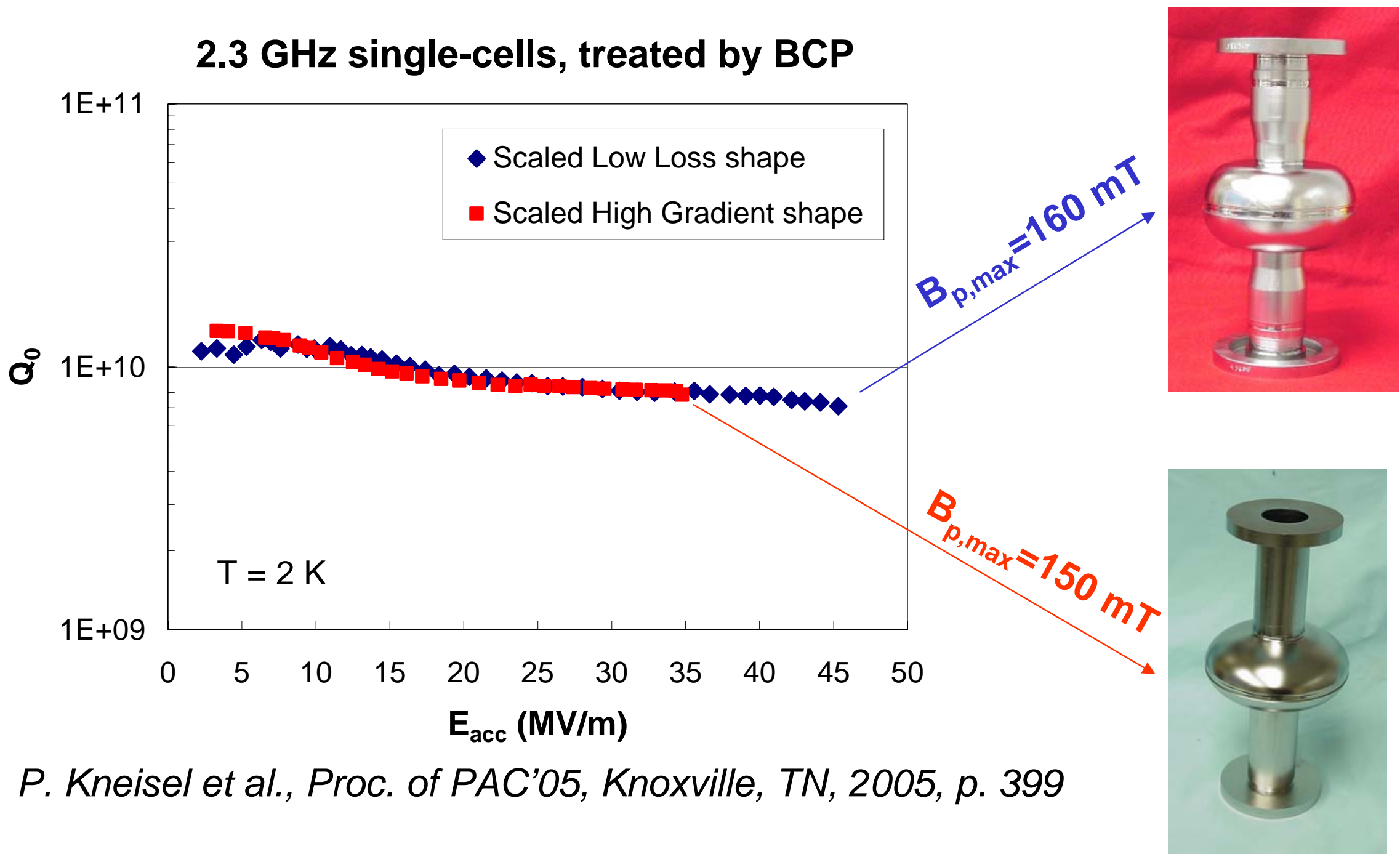




\title{
Test Series
}

\section{Material Comparison with TESLA Single Cells}

\author{
W.C. Heraeus \\ Ningxia \\ CBMM
}




\section{Evaluation of large grain niobium from different vendors}

\begin{tabular}{|l|l|l|l|}
\hline Manufacturer & Ta Contents & RRR & Sheet Cutting Method \\
\hline CBMM & $\sim 800 \mathrm{ppm}$ & $\sim 280$ & Wire EDM \\
\hline W.C.Heraeus & $<500 \mathrm{ppm}$ & $\mathbf{5 0 0}$ & Wire Saw \\
\hline Ningxia & $<100 \mathrm{ppm}$ & 330 & Saw + machining \\
\hline
\end{tabular}




\section{Fabrication and Treatment}

\section{Fabrication}

- Standard deep drawing after cutting of sheets ( wire EDM/CBMM, saw cut/Ningxia, diamond saw/Heraeus)

- Machining

- Welding of beam pipes to half cell

- Mechanical grinding

- Equator weld

Surface Treatment

- 50 micron bcp

- Hydrogen degassing at 600C for $10 \mathrm{hrs}$

- 50 micron bcp, Test \#1

- 12 hrs "in situ” baking at 120C, Test \#2

- 1200 C, 3 hrs post-purification with Ti

- 50 micron bcp, Test \#3

- 12 hrs “in situ” baking at 120C,Test \#4 


\section{CBMM Large Grain Ingot”D”: before post purification}

\section{Large Grain TESLA Cavity Shape SC\#2, Ingot"D"}

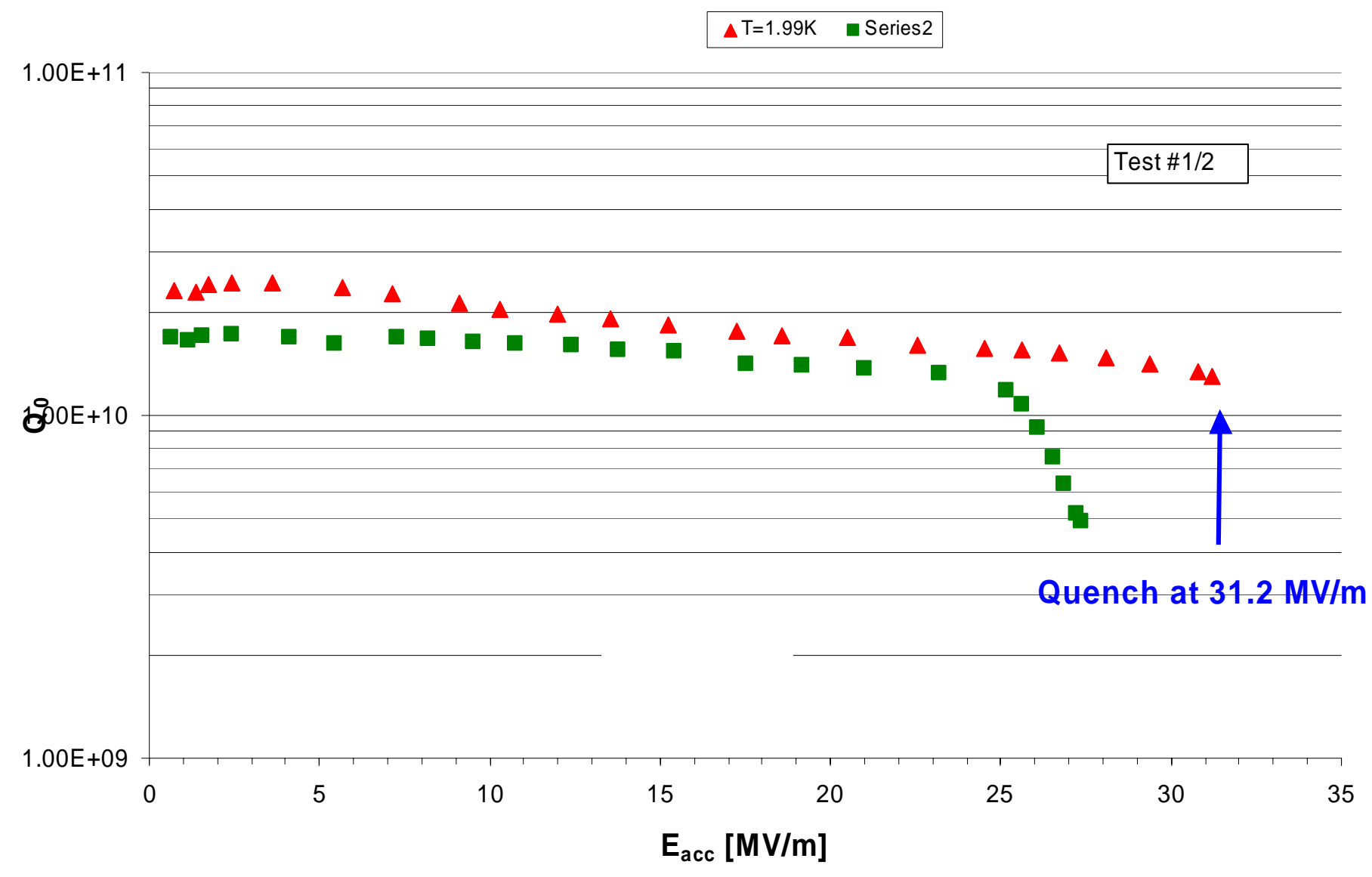

Oct. 30 - Nov. 2, 2006 


\section{Summary before post-purification}

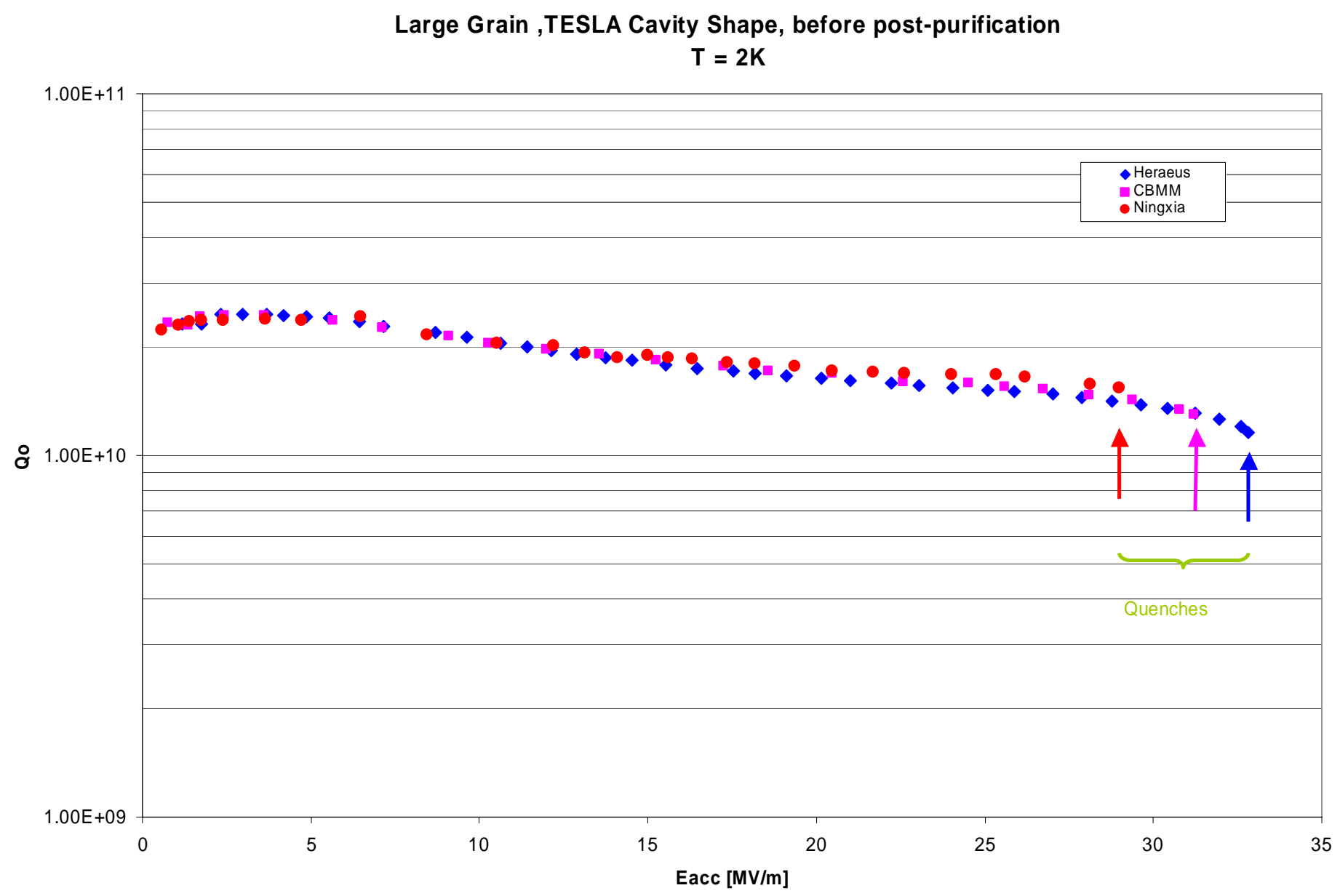

Oct. 30 - Nov. 2, 2006

Single Crystal Workshop

Araxa, Brasil 


\section{Summary after Post-Purification}

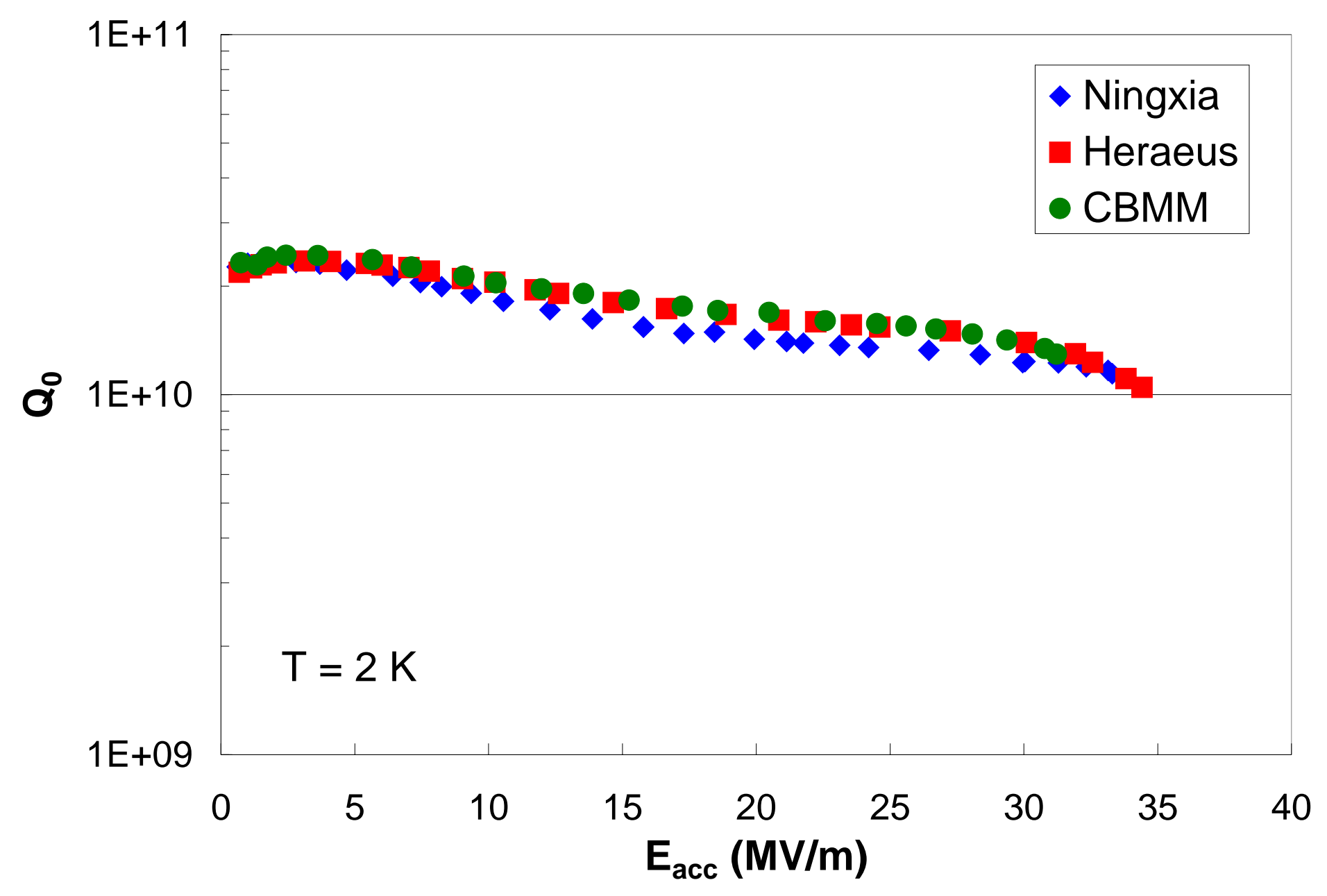




\section{Material Comparison}

\begin{tabular}{|c|c|c|c|c|c|c|c|}
\hline Supplier & Cavity Type & $\begin{array}{l}\text { Ta - } \\
\text { contents }\end{array}$ & RRR & $\begin{array}{l}\text { Test } 1 / 2 \\
H_{\max }[\mathrm{mT}]\end{array}$ & $\begin{array}{l}\text { Test } 1 / 2 \\
\mathrm{Q}_{0} \text { at } \mathrm{H}_{\max }\end{array}$ & \begin{tabular}{|l|}
$\Gamma$ est $3 / 4$ \\
$\mathrm{H}_{\max }|\mathrm{mT}|$
\end{tabular} & $\begin{array}{l}\text { Test } 3 / 4 \\
Q_{0} \text { at } H_{\max }\end{array}$ \\
\hline W.C.Heraueus & TESLA & $<500 \mathrm{ppm}$ & 500 & 140 & $1.15 \times 10^{10}$ & 146 & $1.05 \times 10^{10}$ \\
\hline Ningxia & TESLA & $\sim 100 \mathrm{ppm}$ & 330 & 123 & $1.5 \times 10^{10}$ & 142 & $1.14 \times 10^{10}$ \\
\hline CBMM & TESLA & $\sim 800 \mathrm{ppm}$ & 280 & 133 & $1.3 \times 10^{10}$ & 131 & $1.04 \times 10^{10}$ \\
\hline CBMM & Proton Driver & $\sim 800 \mathrm{ppm}$ & 280 & 139 & $7.5 \times 10^{9}$ & 148 & $6.9 \times 10^{9}$ \\
\hline CBMM & Proton Driver & $\sim 800 \mathrm{ppm}$ & 280 & 133 & $4.4 \times 10^{9}$ & 135 & $1 \times 10^{10}$ \\
\hline
\end{tabular}

Oct. 30 - Nov. 2, 2006

Single Crystal Workshop

Araxa, Brasil 


\section{Summary}

- Materials with different properties (RRR,Ta..) and prepared by different cutting methods behaved very similar after BCP only

- It is not clear yet, what the important features for best performance are

- There is a significant price difference in the different materials

- We are going to fabricate 5 single cell cavities each from Ningxia and W.C.Heraeus material to get some statistics

- The 9-cell cavities for FNAL are being fabricated from CBMM large grain niobium 


\section{Single Crystal TESLA Cavity(DESY/Jlab)}

- This cavity has been fabricated by ACCEL from single crystal W.C.Heraeus RRR niobium under the guidance of Xenia and Waldemar Singer

- The center single crystal was enlarged by rolling with intermediate annealing steps and deep drawing was used for forming of half cells.

- It has been shipped to Jlab for surface treatment and testing

- A test series is in progress, during which successively material is being removed by BCP only, starting at 40 micron after fabrication and the cavity performance is being tested.

- The tests consist of $\mathrm{R}(\mathrm{T})$ and $\mathrm{Q}$ vs E measurement at $2 \mathrm{~K}$ after the BCP treatment and subsequent measurements after "in situ” baking at 120C for 12 hrs. 


\section{Single Crystal Cavity(2) 40 micron bcp}

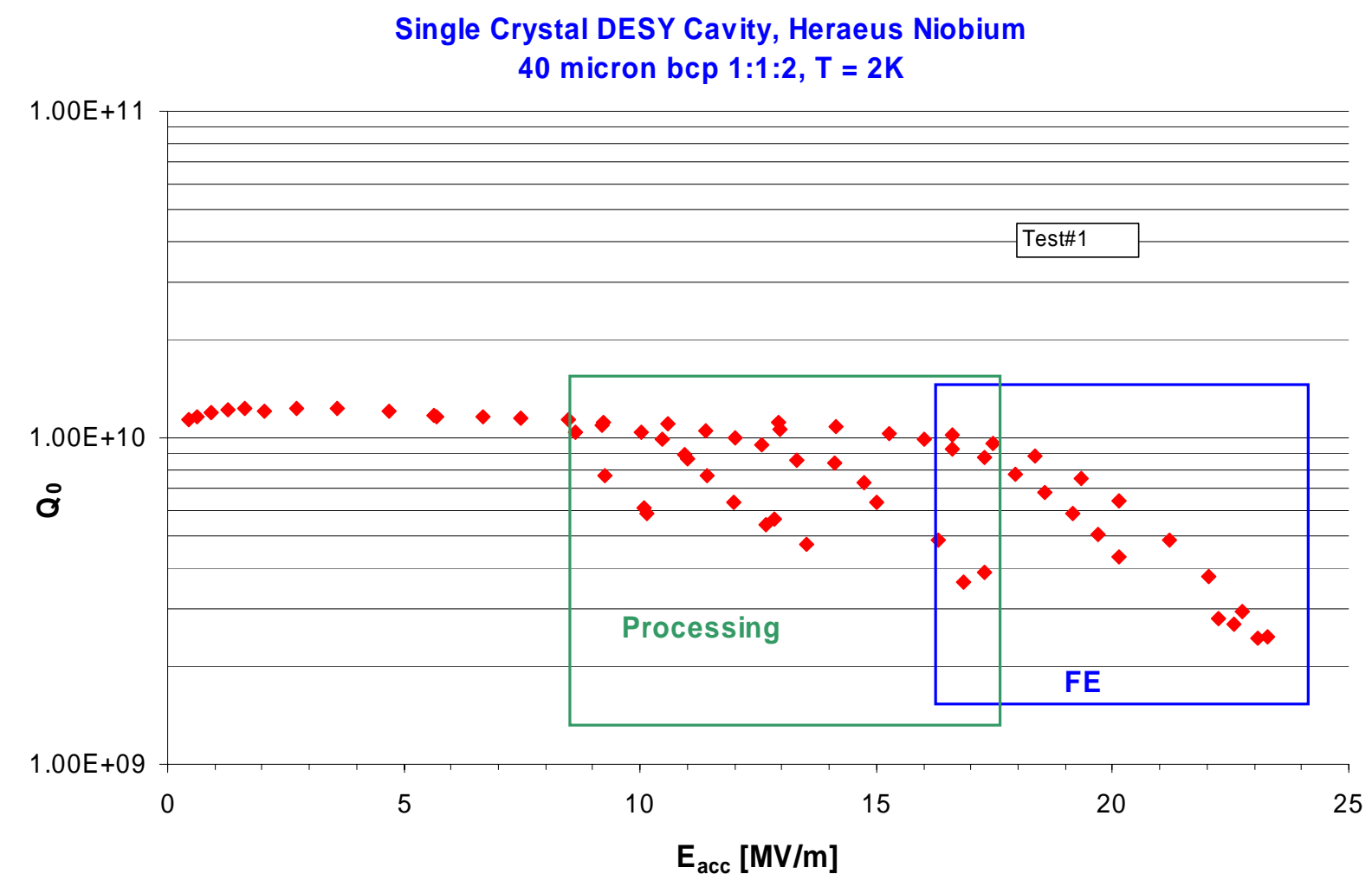

Oct. 30 - Nov. 2, 2006

Single Crystal Workshop

Araxa, Brasil 


\section{Single Crystal Cavity(3)}

\section{0 micron bcp}

Single Crystal DESY Cavity, Heraeus Niobium 60 micron bcp 1:1:2

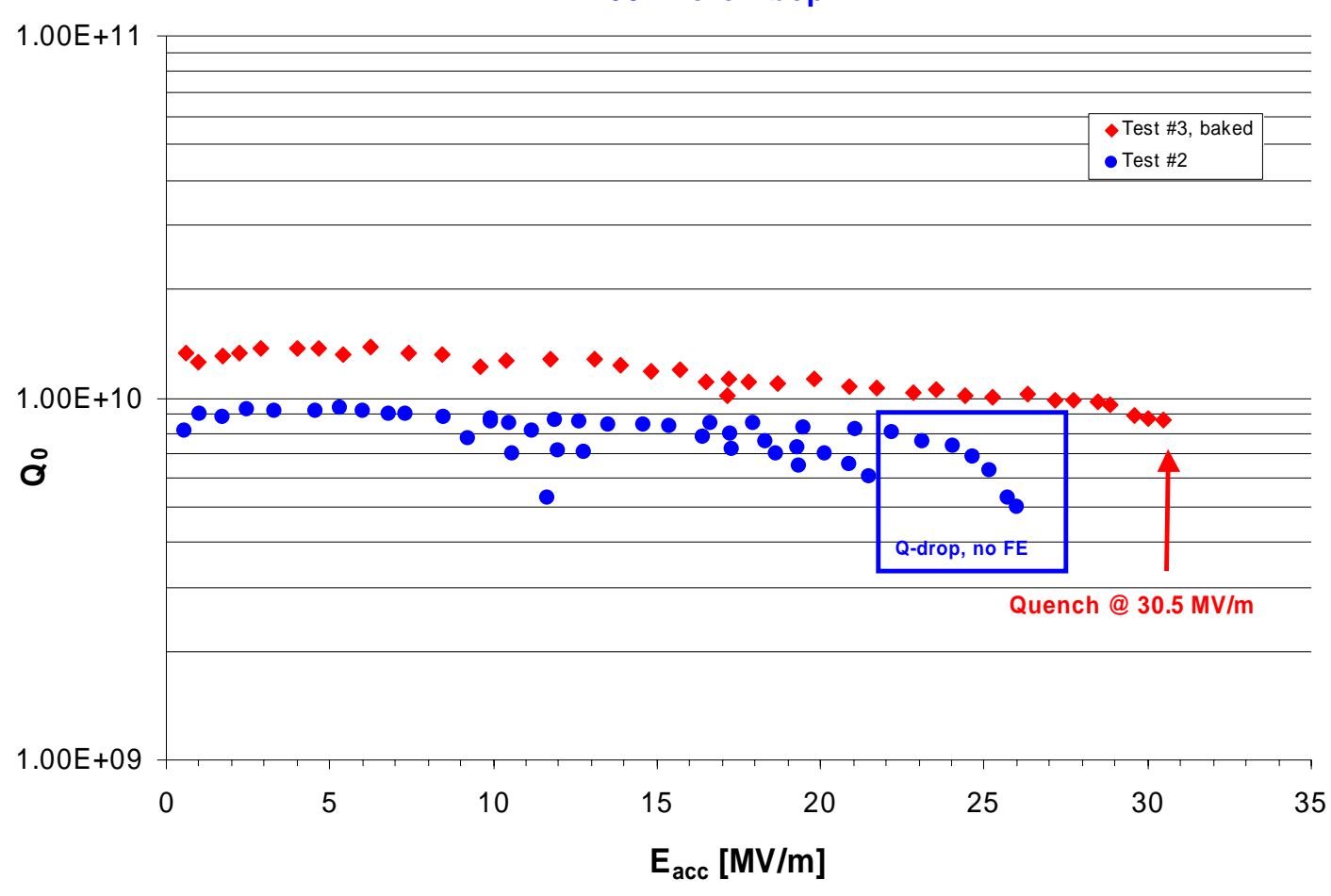

Oct. 30 - Nov. 2, 2006

Single Crystal Workshop

Araxa, Brasil 


\section{Single Crystal Cavity(4)}

Single Crystal DESY Cavity, Heraeus Niobium

80 micron BCP 1:1:2

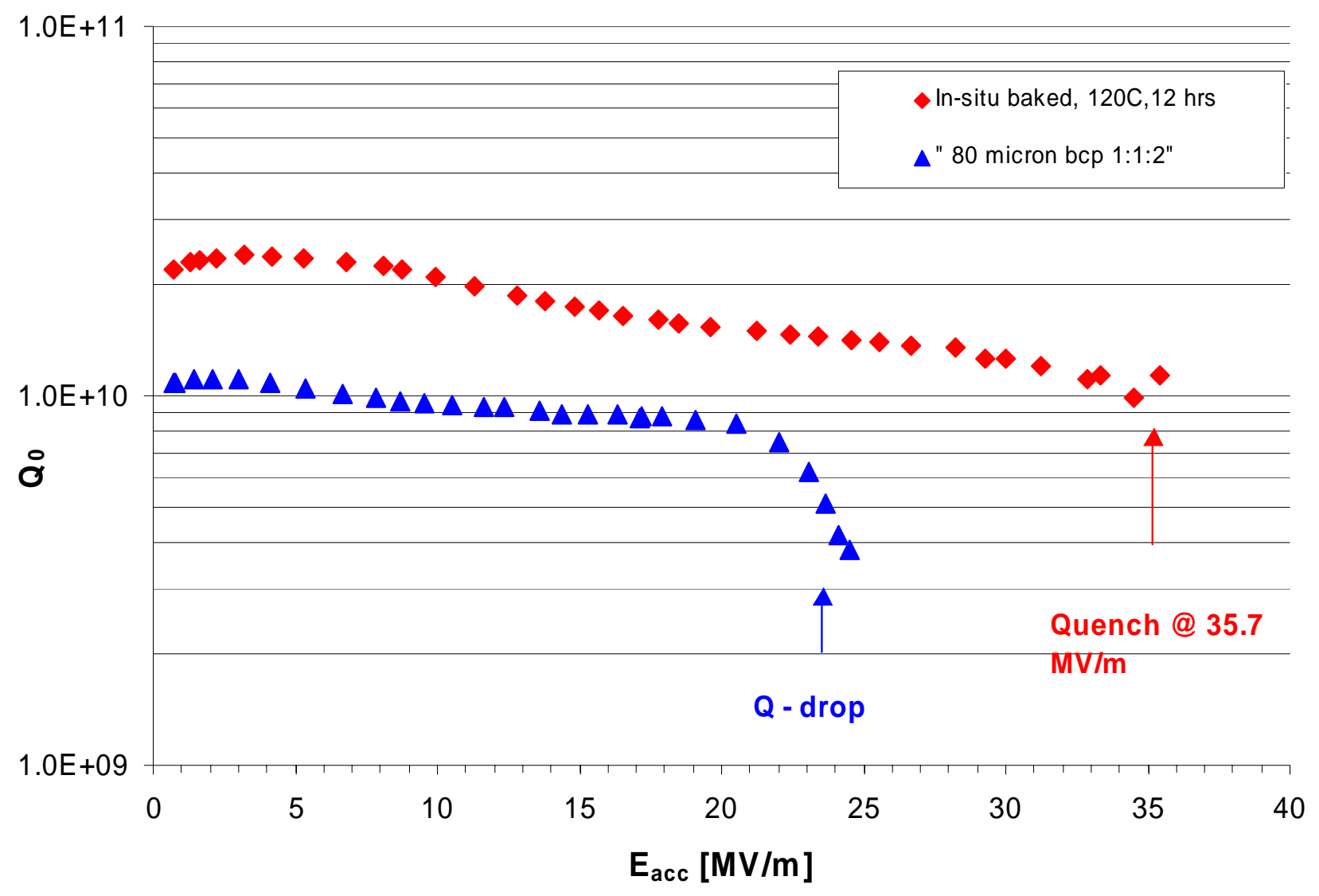

Oct. 30 - Nov. 2, 2006

Single Crystal Workshop

Araxa, Brasil 


\section{Single Crystal Cavity(5)}

Single Crystal DESY Cavity, Heraeus Niobium 112 micron bcp 1:1:2

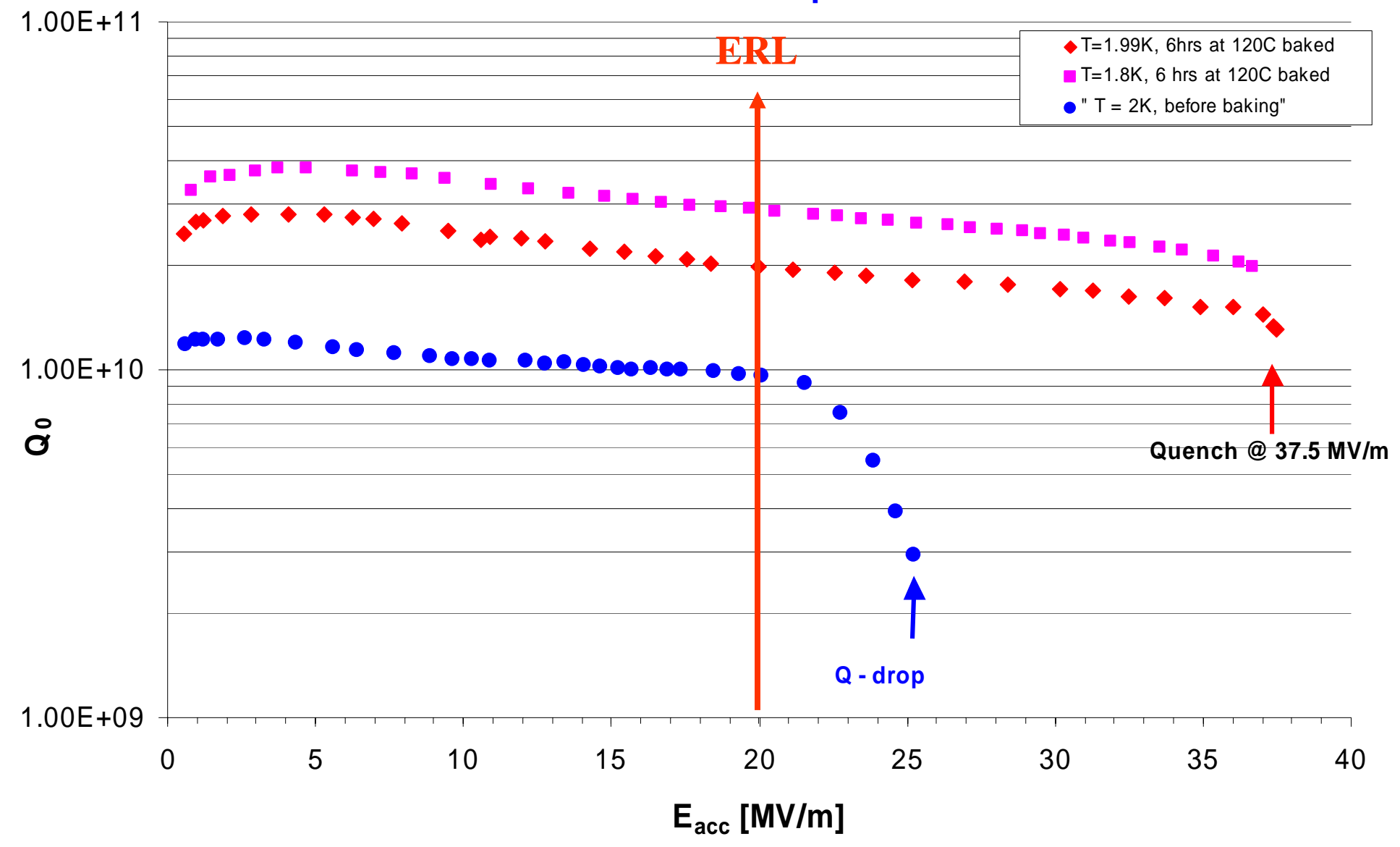

Oct. 30 - Nov. 2, 2006

Single Crystal Workshop

Araxa, Brasil 


\section{Single Crystal(6)}

Single Crystal DESY Cavity, Heraeus Niobium

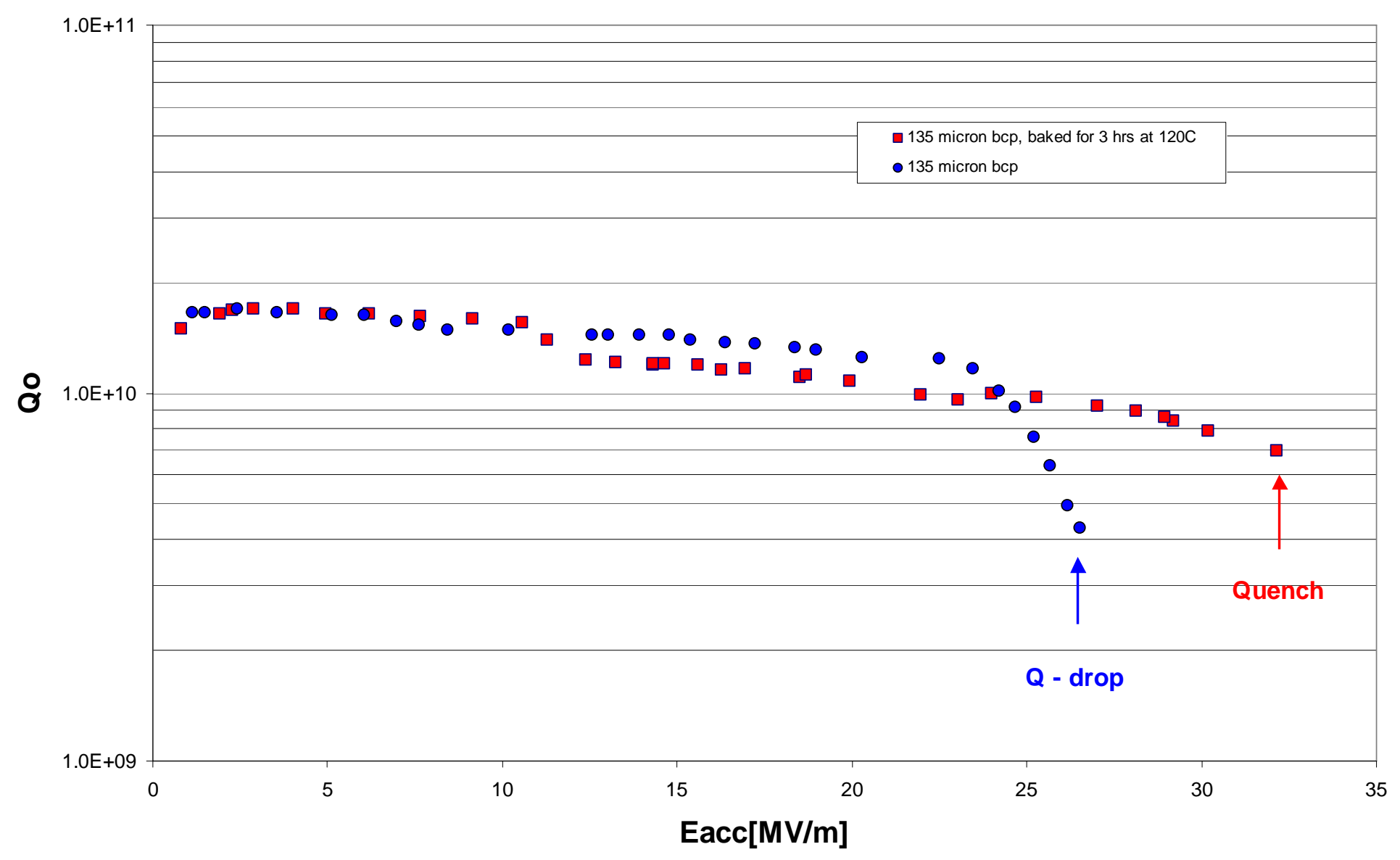

Oct. 30 - Nov. 2, 2006

Single Crystal Workshop

Araxa, Brasil 


\section{"Streamlining of Procedures"}

- BCP 1:1:2 instead of EP

- $50 \%$ of material typical removal ( 112 micron vs $\sim 200$ micron)

- No intermediate furnace treatment after cavity fabrication

- No Q - disease ( not verified)

- Only 6 hrs/or even 3 hrs of "in situ" baking at $120 \mathrm{C}$ vs typically 48 hrs: is this another advantage of large grain/single crystal niobium? 


\section{Baking Time?}

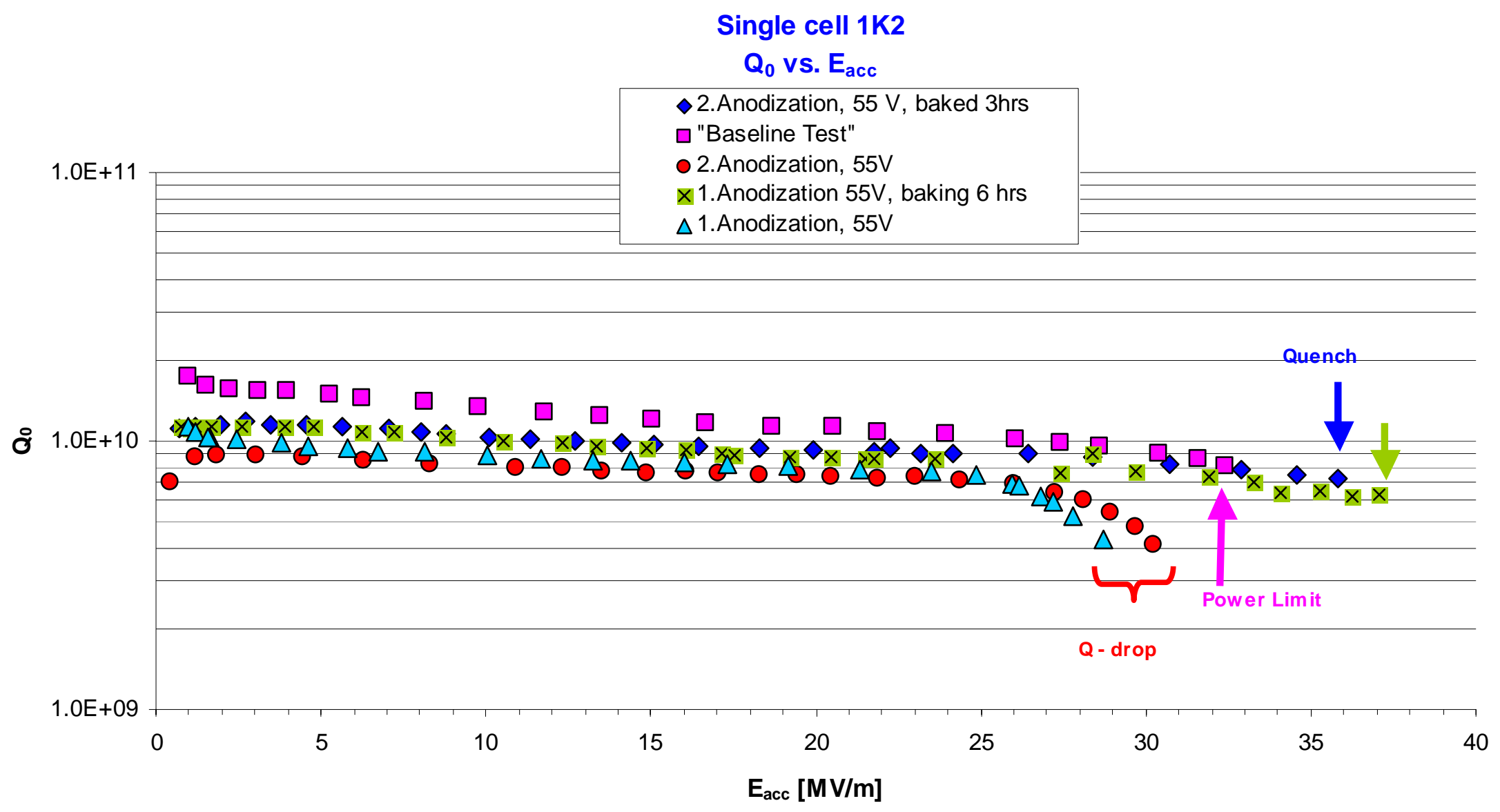

Oct. 30 - Nov. 2, 2006

Single Crystal Workshop

Araxa, Brasil 


\section{Acknowledgement}

This work would not have been possible without the support of several colleagues from Jlab:

Bob Manus

Gary Slack

Larry Turlington

Steve Manning

Pete Kushnick

Isiah Daniels

Danny Forehand 